\title{
Identification of Lewis and Blood Group Carbohydrate Epitopes by Ion Mobility-Tandem-Mass Spectrometry Fingerprinting
}

\author{
Johanna Hofmann ${ }^{\dagger, \neq}$, Alexandra Stuckmann ${ }^{\ddagger}$, Max Crispin $^{\S}$, David J. Harvey ${ }^{\S}$, Kevin Pagel ${ }^{\dagger, \ddagger}, *$ and \\ Weston B. Struwe ${ }^{\S^{*}}$
}

${ }^{\dagger}$ Fritz Haber Institute of the Max Planck Society, Faradayweg 4-6, 14195 Berlin, Germany.

${ }^{\ddagger}$ Institut für Chemie und Biochemie, Freien Universität Berlin, Takustrasse 3, 14195 Berlin, Germany.

${ }^{\S}$ Department of Biochemistry, Glycobiology Institute, University of Oxford, OX1 3QU, United Kingdom

\begin{abstract}
Glycans have several elements that contribute to their structural complexity, involving a range of monosaccharide building blocks, configuration of linkages between residues and various degrees of branching on a given structure. Their analysis remains challenging and resolving minor isomeric variants can be difficult, in particular terminal fucosylated Lewis and blood group antigens present on $\mathrm{N}$ - and $\mathrm{O}$-glycans. Accurately characterizing these isomeric structures by current techniques is not straightforward and typically requires a combination of methods and/or sample derivatization. Yet the ability to monitor the occurrence of these epitopes is important as structural changes are associated with several human diseases. The use of ion mobility-mass spectrometry (IM-MS), which separates ions in the gas phase based on their size, charge and shape, offers a new potential tool for glycan analysis and recent reports have demonstrated its potential for glycomics. Here we show that Lewis and blood group isomers, which have identical fragmentation spectra, exhibit very distinctive IM drift times and collision cross sections (CCS). We show that IM-MS/MS analysis can rapidly and accurately differentiate epitopes from parotid N-glycans and milk oligosaccharides based on fucosylated fragment ions with characteristic CCSs.
\end{abstract}

Analysis of glycoconjugates remains a particular challenge in structural biology due to their vast complexity and intricate biosynthesis. Yet the ability to monitor the occurrence of specific carbohydrate markers or changes in protein glycosylation is very important, because they are regularly associated with disease states such as cancer metastasis ${ }^{1,2}$. This variation in glycosylation is due to cellular changes that affect the non-template driven glycosylation pathway in the endoplasmic reticulum and Golgi apparatus among all nascent glycoproteins. Subtle changes in glycan structures can influence protein function, localization or interactions. These differences arise not only from variations in the number and types of monosaccharide residues, but also from the linkages between them.

One of the most familiar examples of isomeric glycoconjugates are the ABO and Lewis blood group systems. They contain carbohydrate epitopes which consist of a core structure of galactose (Gal) and $N$-acetylglucosamine (GlcNAc) with differently attached fucose (Fuc) residues. These are mediated in individuals by expression of $\alpha 1,2$-fucosyltransferases and/or $\alpha 1,3 / 4$-fucosyltransferases and result in different defined glycan antigens throughout the body. The altered expression of ABO and Lewis glycosyltransferases and changes in glycan structures are commonly associated with cancer formation and regression. ${ }^{3-11}$ The carbohydrate antigen CA19.9, which is specific for sialylated Lewis a $\left(\mathrm{Le}^{\mathrm{a}}\right)$ epitopes, is the only FDA approved biomarker for pancreatic ductal adenocarcinoma screening, but there are concerns with its use including specificity, levels of detection and non-expression in $L e^{-}$patients. ${ }^{12}$ The ability to discern subtle changes in fucosylation, which are observed in disease progression and host-pathogen interactions is, therefore, decidedly important but also analytically challenging.

There are several strategies used for characterizing terminal fucose linkages, but each approach has inherent drawbacks and is not always comprehensive. For example, sequential mass spectrometry $\left(\mathrm{MS}^{\mathrm{n}}\right)$ following sample permethylation ${ }^{13,14}$ is highly informative but requires glycan derivatization and is not highthroughput nor as sensitive as HPLC and LC-MS methods. ${ }^{15,16}$ Conversely, HPLC with fluorescence detection requires sequential treatment with numerous exoglycosidase enzymes and the limited availability of linkage-specific fucosidases hinders coverage of these epitopes. Porous graphitized carbon LC-MS ${ }^{2}$ of negative glycan ions can effectively separate isomers and diagnostic fragmentation help pinpoint structures. ${ }^{17}$ However, fragmentation data are not always inclusive and, therefore, not all fucose linkages can be resolved, particularly $\mathrm{Le}^{\mathrm{a} / \mathrm{x}}$ and $\mathrm{Le}^{\mathrm{b} / \mathrm{y}}$ structural isomers. ${ }^{18}$ An additional complication in the analysis of Lewis antigens is migration and rearrangement of fucose residues along the glycan antennae during collision-induced dissociation (CID) of protonated glycan ions. ${ }^{19,20}$ It was reported that $\alpha 1,3$-fucose residues migrated to neighbouring $\mathrm{Le}^{\mathrm{x}}$ epitopes leading to false identification of $\mathrm{Le}^{\mathrm{y}}$ structures but this occurrence was not seen with sodiated glycans which is the focus of this study.

Ion mobility-mass spectrometry (IM-MS) has shown promising results in its capacity to separate isomeric carbohydrates that cannot be resolved by orthogonal methods. To date the use of IM for glycomics has been shown for small oligosaccharides, 
intact N-glycans, and glycosaminoglycans. ${ }^{21-29}$ In IM, ions travel through a gas-filled cell aided by an electric field and are separated based on their charge, size, and shape. Gas phase glycan ions adopt distinct structures which allow the separation of isomeric species. In addition, IM drift times can be used to calculate rotationally averaged collision cross sections (CCSs), which are absolute, instrument independent values that can be used for glycan identification.

Here we use IM-MS to differentiate Lewis and blood group epitope isomers, which have identical MS/MS spectra, but display different IM drift times. Furthermore, we take advantage of the ability to generate glycan fragments by CID prior to IM to obtain additional CCS values of fragment ions. This method provides a dual set of $\mathrm{m} / \mathrm{z}$ and CCS information, which can be used to identify blood group (BG)/Le epitopes by fragmentation of larger glycoconjugates. We demonstrate that this integrated approach can rapidly distinguish BG/Le motifs in milk oligosaccharides and parotid N-glycans without sample derivatization and show that glycans can effectively be identified by their diagnostic fragment CCS fingerprints.

\section{EXPERIMENTAL SECTION}

Synthetically derived Lewis and blood group oligosaccharides were purchased from Dextra Laboratories (Reading UK), with the exception of BG- $\mathrm{H}^{1}$, which was purchased from Elicityl SA (Crolles, France), and diluted with HPLC grade water to a final concentration of $150 \mu \mathrm{M}$ prior to use. $1 \mu \mathrm{l}$ from the stock solution was added to $8 \mu 1$ 1:1 methanol/water (HPLC grade) and 1 $\mu 10.1 \%$ formic acid to promote proton adduct formation. Fucosyllacto-N-hexaose (FLNH), difucosyllacto-N-hexaose (DFLNH) and trifucosyllacto-N-hexaose (TFLNH) milk oligosaccharides were purchased from Sigma Chemical Co. Ltd. (Poole, Dorset, UK). Milk oligosaccharides stock solutions were prepared with a concentration of $100 \mathrm{ng} / \mu \mathrm{l}$ in water. Prior to analysis, $1 \mu 1$ was added to $19 \mu 1$ water/methanol (50:50 v/v). Parotid N-glycans were isolated from tissue as previously described ${ }^{30} \mathrm{~N}$-glycans were released chemically by hydrazinolysis and subsequently re- $N$-acetylated. Sample solutions were stored at $-20^{\circ} \mathrm{C}$ until analysis.

Ion Mobility-Mass Spectrometry. Traveling wave (TW) IMMS measurements were performed on a Synapt G2Si instrument (Waters, Manchester, UK). For each analysis $2 \mu \mathrm{l}$ of sample were ionized by nano-electrospray ionization (nano-ESI) from gold-coated borosilicate glass capillaries prepared inhouse. ${ }^{31}$ Instrument settings were as follows: capillary voltage, 0.8-1.0 kV; sample cone, $100 \mathrm{~V}$; extraction cone, $25 \mathrm{~V}$; cone gas, $40 \mathrm{l} / \mathrm{h}$; source temperature, $150{ }^{\circ} \mathrm{C}$; trap collision voltage, 4-160 V; transfer collision voltage, $4 \mathrm{~V}$; trap DC bias, 35-65 V; IMS wave velocity, $450 \mathrm{~m} / \mathrm{s}$; IMS wave height, $40 \mathrm{~V}$; trap gas flow, $2 \mathrm{ml} / \mathrm{min}$; IMS gas flow, $80 \mathrm{ml} / \mathrm{min}$. Data was acquired and processed with MassLynx v4.1 and Driftscope version 2.8 software (Waters, Manchester, UK), and OriginPro 8.5 (OriginLab Corporation, Northampton).

TW-IM-MS and Collision Cross Section Estimation. Arrival time distributions (ATDs) were fit to a single or double Gaussian distribution prior to estimating experimental ${ }^{\mathrm{TW}} \mathrm{CCSs}$. A dextran calibration ladder with known absolute drift tube ${ }^{\mathrm{DT}} \mathrm{CCS}$ was used for estimating $\mathrm{N}$-glycan ${ }^{\mathrm{TW}} \mathrm{CCS}$ values as previously described. ${ }^{32,33}$ Briefly, measured drift times $\left(t_{D}\right)$ were corrected for $m / z$ dependent delay time from Equation 1 where $c$ is an empirically determined constant ( $c=0.001 \times$ EDC (enhanced duty cycle) delay coefficient).
$\mathrm{t}_{\mathrm{D}}^{\prime}=\mathrm{t}_{\mathrm{D}}-\mathrm{c} \sqrt{\mathrm{m} / \mathrm{z}}$

Absolute dextran ${ }^{\mathrm{DT}} \mathrm{CCS}$ were corrected for charge $(\mathrm{z})$ and reduced mass $(\mu)$ of the ion and the drift gas (Equation 2).

$$
\mathrm{CCS}^{\prime}={ }^{\mathrm{DT}} \mathrm{CCS} /\left[\mathrm{z} \times\left(\frac{1}{\mu}\right)^{\frac{1}{2}}\right]
$$

A linear correlation plot of $\ln \left(\mathrm{CCS}^{\prime}\right)$ versus $\ln \left(\mathrm{t}^{\prime}{ }_{\mathrm{D}}\right)\left(\mathrm{R}^{2}>0.99\right)$ gives two constants termed the fit-determined constant $A$ and the slope $X$ from the equation:

$\ln \mathrm{CCS}^{\prime}=\mathrm{X} \times \ln \mathrm{t}_{\mathrm{D}}+\ln \mathrm{A}$

Estimated ${ }^{\mathrm{TW}} \mathrm{CCS}$ values can then be determined from experimental drift times by Equation 4, derived from combining Equation 2 and 3 ( ${ }^{\mathrm{DT}} \mathrm{CCS}$ now replaced with ${ }^{\mathrm{TW}} \mathrm{CCS}$ ):

${ }^{\mathrm{TW}} \mathrm{CCS}=\mathrm{A} \times \mathrm{z} \times \mathrm{t}_{\mathrm{D}}^{\prime}{ }^{X} \times\left(\frac{1}{\mu}\right)^{\frac{1}{2}}$

All TW-IM CCS data are deposited in the GlycoMob database. ${ }^{34}$ Sample preparation and MS reporting are in accordance with MIRAGE guidelines ${ }^{35,36}$.

\section{RESULTS AND DISCUSSION}

IM-MS of Intact Le and BG Epitope Precursors. The separation potential of individual Lewis and blood group oligosaccharides $\left(\mathrm{Le}^{\mathrm{a}}, \mathrm{Le}^{\mathrm{x}}, \mathrm{BG}-\mathrm{A}, \mathrm{BG}-\mathrm{H}^{1}, \mathrm{BG}-\mathrm{H}^{2}, \mathrm{Le}^{\mathrm{b}}\right.$ and $\left.\mathrm{Le}^{\mathrm{y}}\right)$ was first tested for intact ions by traveling wave ion mobility (TW-IM) (Figure 1). $\mathrm{Le}^{\mathrm{a}}, \mathrm{Le}^{\mathrm{x}}, \mathrm{BG}-\mathrm{H}^{1}$ and $\mathrm{BG}-\mathrm{H}^{2}$ are isomeric trisaccharides consisting of fucose (Fuc), galactose (Gal) and $N$-acetylglucosamine (GlcNAc) residues. BG-A is an isomeric structure which differs in regio- and stereochemistry. Aside from fucose and galactose it additionally contains $N$-acetylgalactosamine (GalNAc) instead of GlcNAc.

Le and BG epitopes are structural similar and contain a core in which Gal and GlcNAc are either connected via a $\beta 1 \rightarrow 3$ or a $\beta 1 \rightarrow 4$ linkage resulting in so-called type 1 and 2 structures,

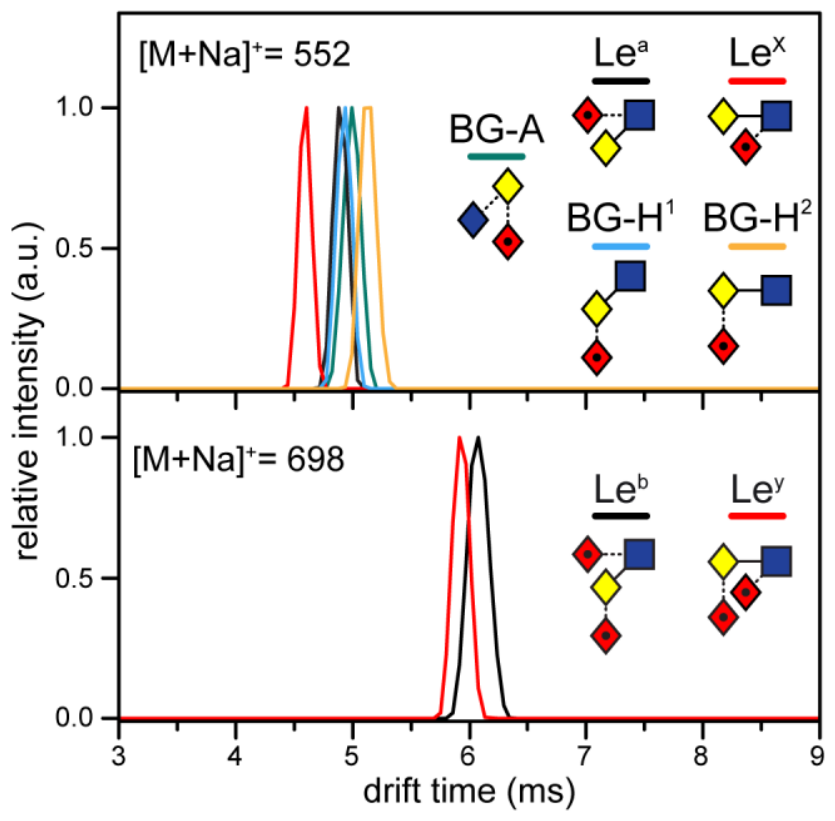

Figure 1. Arrival time distributions (ATDs) of Lewis and blood group oligosaccharides measured as sodium adducts. Trisaccharide isomers $\mathrm{Le}^{\mathrm{a}}$, Le ${ }^{\mathrm{x}}, \mathrm{BG}-\mathrm{A}, \mathrm{BG}-\mathrm{H}^{1}, \mathrm{BG}-\mathrm{H}^{2}$ (upper panel) and tetrasaccharide isomers $\mathrm{Le}^{\mathrm{b}}$ and $\mathrm{Le}^{\mathrm{y}}$ are shown (lower panel). Glycan structures are represented using the Oxford system ${ }^{37}(\diamond=$ GalNAc, $=$ GlcNAc, $\diamond=$ Gal, $\diamond=$ Fuc). 
respectively. The attachment of fucose leads to BG-H structures via $\alpha 1 \rightarrow 2$ linkages, Le ${ }^{\mathrm{x}}$ via $\alpha 1 \rightarrow 3$ linkages, and $\mathrm{Le}^{\mathrm{a}}$ via $\alpha 1 \rightarrow 4$ linkages. The exception is the BG-A structure where the fucose is attached as penultimate residue to a GalNAc-Gal core motif. $\mathrm{Le}^{\mathrm{b}}$ and $\mathrm{Le}^{\mathrm{y}}$ are tetrasaccharide isomers similar to $\mathrm{Le}^{\mathrm{a}}$ and $\mathrm{Le}^{\mathrm{x}}$ structures, respectively, but containing two fucose residues.

When analysing these structures using IM-MS, different arrival time distributions (ATDs) were observed among sodium adduct ions: for trisaccharides $(\mathrm{m} / z, 552) \mathrm{Le}^{\mathrm{a}}(4.90 \mathrm{~ms}), \mathrm{Le}^{\mathrm{x}}(4.59 \mathrm{~ms})$, BG-A (5.00 ms), BG-H ${ }^{1}(4.93 \mathrm{~ms}),{\mathrm{BG}-\mathrm{H}^{2}}(5.13 \mathrm{~ms})$ and tetrasaccharides $\left(m / z\right.$ 698) Le ${ }^{\mathrm{b}}(6.08 \mathrm{~ms})$ and Le $\mathrm{L}^{\mathrm{y}}(5.93 \mathrm{~ms})$ (Figure 1). Notable is the difference between $\mathrm{Le}^{\mathrm{x}}$ and $\mathrm{Le}^{\mathrm{a}}$, which were nearly baseline separated despite minor structural differences (Fuc and Gal linkages are switched). $\mathrm{Le}^{\mathrm{x}}$ had a much earlier drift time compared to other trisaccharides and the $\mathrm{BG}-\mathrm{H}^{1} / \mathrm{BG}-\mathrm{H}^{2}$ isomers also differed, but not as much as $\mathrm{Le}^{\mathrm{x}} / \mathrm{Le}^{\mathrm{a}}$. Intact tetrasaccharide $[\mathrm{M}+\mathrm{Na}]^{+}$adducts could also be differentiated, where the drift time of $\mathrm{Le}^{\mathrm{y}}$ (5.93 ms) was shorter than of Le ${ }^{\mathrm{b}}(6.08 \mathrm{~ms})$. The observation that both $\mathrm{Le}^{\mathrm{x}}$ and $\mathrm{Le}^{\mathrm{y}}$ had the lowest drift times implies they adopt more compact gas-phase structures and may correlate with $\alpha 1 \rightarrow 3$ fucose linkages that are present on both ions. Overall the results show that IM can distinguish Le and BG isomers as sodium adduct ions by TW-IM-MS.

IM-MS of Le and BG Epitope Fragment Ions. Next we explored IM separation of fragment ions using a Synapt HDMS instrument that permits CID before and/or after IM separation in the trap or transfer region, respectively (Figure 2). With transfer CID, all fragments are time-aligned with the parent ions while with trap CID, fragments can be resolved according to their CCS. MS/MS of Le and BG $[\mathrm{M}+\mathrm{Na}]^{+}$ions resulted primarily in the neutral loss of fucose residues (Le ${ }^{\mathrm{b}} / \mathrm{Le}^{\mathrm{y}}: \mathrm{m} / \mathrm{z}$

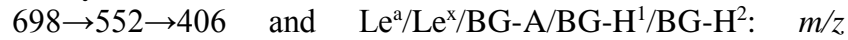
$552 \rightarrow 406) \quad$ (Figure $\mathrm{S}-1$ ). These spectra

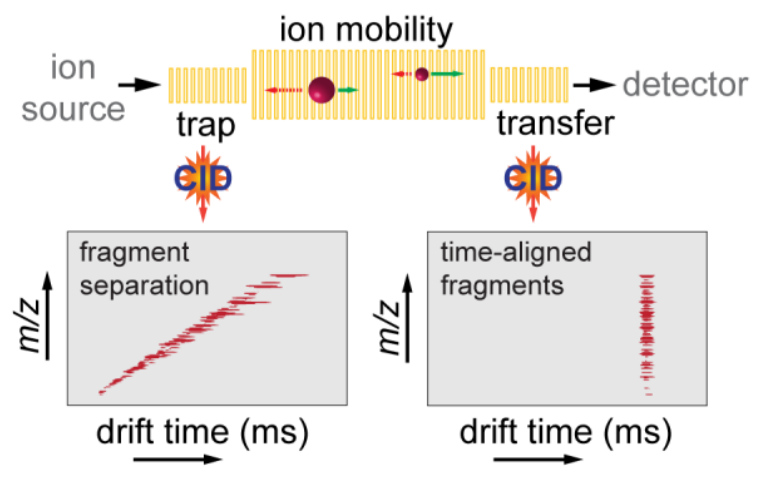

Figure 2. Schematic of a TW-IM-MS instrument depicting IM separation properties of glycan fragment ions for either trap or transfer CID.

were identical, yet the drift times of fragment ions are remarkably different (Figure 3). Most noticeable was $\mathrm{Le}^{\mathrm{y}}$, which yielded four drift peaks from three fragment ions $(\mathrm{m} / \mathrm{z}$ 698, 552 and 406), with two peaks arising from the $m / z 552$ fragment. These $m / z, 552$ fragments arise from a $\alpha 1 \rightarrow 2$ fucose or $\alpha 1 \rightarrow 3$ fucose loss and yield fragment structures that are similar to those of the intact $\mathrm{Le}^{\mathrm{x}}$ and $\mathrm{BG}-\mathrm{H}^{2}$ precursors, respectively. As a result, the ATDs of the $\mathrm{Le}^{\mathrm{y}} \mathrm{m} / z, 552$ fragments (4.61 and 5.12 $\mathrm{ms}$ ) align very well with the drift times of parent $\mathrm{Le}^{\mathrm{x}}$ and BG$\mathrm{H}^{2}$ epitopes. In addition, the drift time of the $m / z, 406$
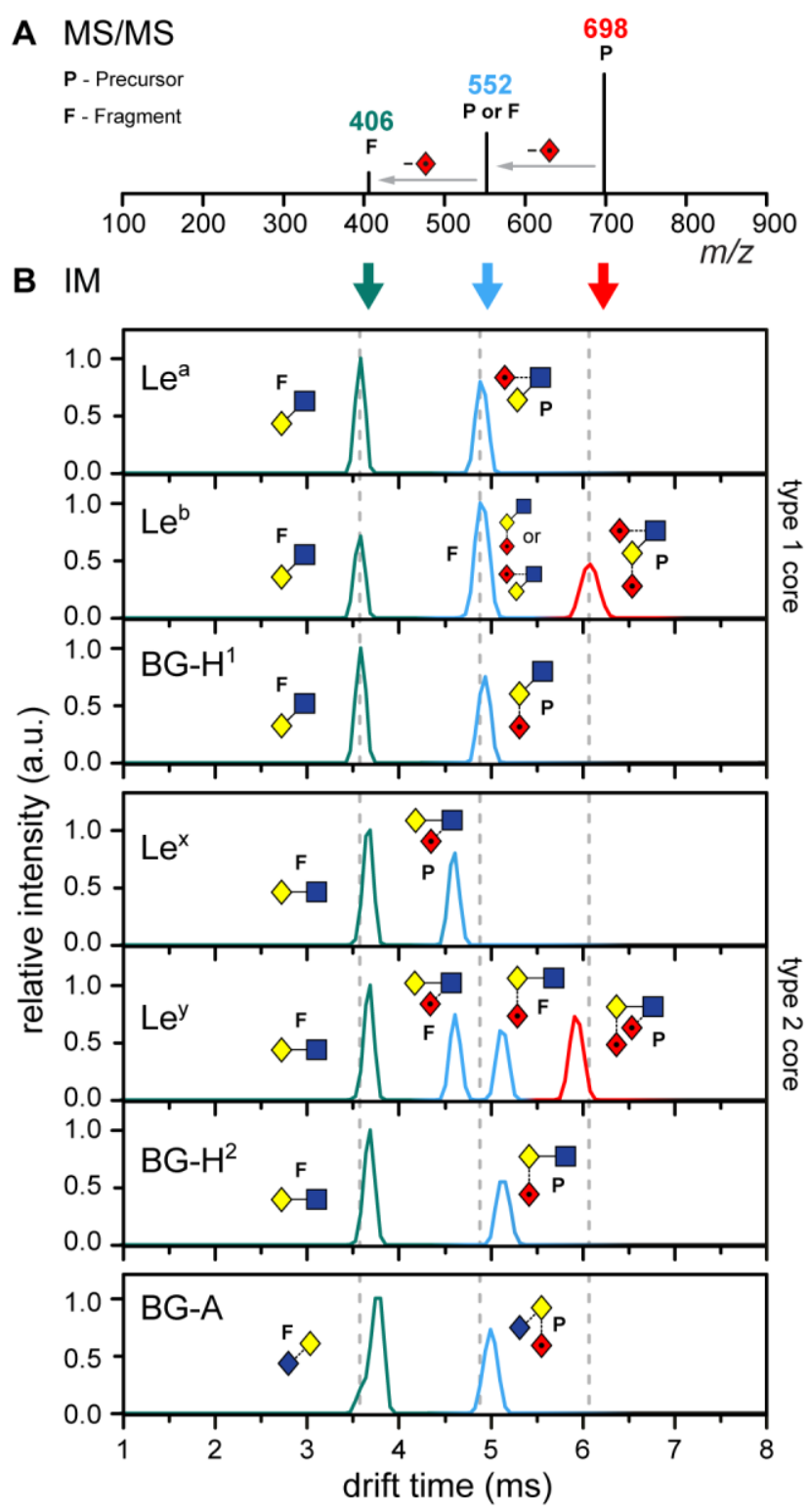

Figure 3. Tandem MS spectra (A) and IM arrival time distributions (B) of Lewis and blood group precursor and fragment ions as $[\mathrm{M}+\mathrm{Na}]^{+}$species. The major fragments resulted from the neutral loss of fucose from the parent ions at $\mathrm{m} / \mathrm{z} 698$ and 552 .

ion (Gal $\beta 1-4$ GlcNAc) from $\mathrm{Le}^{\mathrm{y}}$ was equal to the $\mathrm{m} / \mathrm{z} 406$ fragment from $\mathrm{Le}^{\mathrm{x}}$ and $\mathrm{BG}-\mathrm{H}^{2}$, which is expected as they all correspond to the same type 1 core structure. In contrast to the good separation of fragments arising from $\mathrm{Le}^{\mathrm{y}}$, the IM spectrum of $\mathrm{Le}^{\mathrm{b}}$ fragment ions showed only three peaks, one for each MS/MS ion. A single drift peak at $4.96 \mathrm{~ms}$ is observed for the $\mathrm{m} / \mathrm{z} 552$ fragment, which could be loss of $\alpha 1 \rightarrow 2$ fucose or $\alpha 1 \rightarrow 4$ fucose with fragment structures similar to intact $\mathrm{Le}^{\mathrm{a}}$ and $\mathrm{BG}-\mathrm{H}^{1}$ precursors, respectively. This behaviour, however, was expected since the intact $\mathrm{Le}^{\mathrm{a}}$ and $\mathrm{BG}-\mathrm{H}^{1}$ trisaccharides had very similar drift times, which did not allow separation. The 552 ATD from $\mathrm{Le}^{\mathrm{b}}$ is, therefore, likely to arise from a mixture of both fragment structures (Fuc $\alpha 1 \rightarrow 2 \mathrm{Gal} \beta 1 \rightarrow 3 \mathrm{GlcNAc}$ and Fuc $\alpha 1 \rightarrow 4($ Gal $\beta 1 \rightarrow 3)$ GlcNAc). The $m / z \quad 406$ ions (Gal $\alpha 1 \rightarrow 3$ GalNAc) that are formed from $\mathrm{Le}^{\mathrm{b}}, \mathrm{BG}-\mathrm{H}^{1}$ and $\mathrm{Le}^{\mathrm{a}}$ structures on the other hand, all correspond to the same type 2 
Table 1. Estimated collision cross sections for the drift gas nitrogen $\left({ }^{\mathrm{TW}} \mathrm{CCS}_{\mathrm{N} 2}\right)$ of Lewis and blood group precursor and fragment ions as $[\mathrm{M}+\mathrm{Na}]^{+}$ions. ${ }^{\mathrm{TW}} \mathrm{CCS}_{\mathrm{N} 2}$ values represent the average of three independent measurements and their standard deviation. Fuc-Gal fragments $(m / z, 349)$ are not available for $\mathrm{Le}^{\mathrm{a}}$ and $\mathrm{Le}^{\mathrm{x}}$ structures. Glycan structures are represented using the Oxford system as defined in Figure 1 legend.

\begin{tabular}{|c|c|c|c|c|c|c|}
\hline & \multicolumn{6}{|c|}{ parent and fragment ion ${ }^{\mathrm{TW}} \mathrm{CCS} S_{\mathrm{N} 2}\left(\AA^{2}\right)$} \\
\hline $\mathrm{m} / \mathrm{z}$ & 349 & 406 & 534 & 552 & 680 & 698 \\
\hline type & $C /{ }^{*} \mathrm{Y}$ & $Y$ & $\mathrm{Z} /-\mathrm{H}_{2} \mathrm{O}$ & $Y /$ intact & $-\mathrm{H}_{2} \mathrm{O}$ & intact \\
\hline $\mathrm{Le}^{\mathrm{a}}$ & - & $\begin{array}{c}\delta^{n} \\
189 \pm 1\end{array}$ & $\begin{array}{c}0 \\
219 \pm 2\end{array}$ & $\begin{array}{c}-0 \\
223 \pm 2\end{array}$ & & \\
\hline $\operatorname{Le}^{b}$ & $\stackrel{8}{179 \pm 2}$ & $\begin{array}{c}\delta^{\square} \\
190 \pm 2\end{array}$ & 品 & 品 & 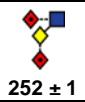 & $252 \pm 1$ \\
\hline$B G-H^{1}$ & $\bigotimes_{180 \pm 1}$ & $\begin{array}{c}\nabla \\
188 \pm 1\end{array}$ & $\sum_{218 \pm 2}^{\square}$ & $\aleph_{224 \pm 1}$ & & \\
\hline $\operatorname{Le}^{x}$ & - & $\begin{array}{c}\diamond \\
191 \pm 1\end{array}$ & $\begin{array}{c}- \\
217 \pm 2\end{array}$ & $\begin{array}{c}\checkmark \\
215 \pm 2\end{array}$ & & \\
\hline $\operatorname{Le}^{y}$ & $\underset{179 \pm 1}{\grave{P}}$ & $\begin{array}{c}\Delta-\square \\
192 \pm 2\end{array}$ & ৫ & $\begin{array}{cc}\diamond & -\square \\
216 \pm 1 & 229 \pm 1\end{array}$ & $247 \pm 1$ & $\begin{array}{c}-\bar{c} \\
248 \pm 1\end{array}$ \\
\hline$B G-H^{2}$ & $\stackrel{8}{179 \pm 1}$ & $\begin{array}{c}\diamond \square \\
191 \pm 1\end{array}$ & $\begin{array}{c}-\square \\
219 \pm 2\end{array}$ & & & \\
\hline BG-A & $\diamond_{177 \pm 2}^{*}$ & $\begin{array}{c}\diamond \\
193 \pm 2\end{array}$ & $\begin{array}{c}\Delta, \\
222 \pm 2\end{array}$ & $225 \pm 1$ & & \\
\hline
\end{tabular}

epitopes and, as a result, exhibit a similar drift time, which is slightly smaller than that observed for type 1 fragments. MS/MS of BG-A also yields a $\mathrm{m} / z, 406$ fragment ion, which structurally, however, neither corresponds to those observed for a type 1 nor a type 2 core structure. As a result, the Gal $\alpha 1 \rightarrow 3$ GalNAc fragment from BG-A differed in drift time from both Gal-GlcNAc structures, which underlines that this disaccharide is also diagnostic in IM.

CCSs of Epitope Fragment Ions. The different ATDs of Le and BG parent and fragment ions support IM as a robust method to identify these epitopes. However, analogous to HPLC retention times, ion mobility drift times can vary considerably between instruments/laboratories. To ensure consistent and accurate application of the method it is, therefore, more practical to compare CCSs, which are absolute values for each glycan ion and can be used as standard values for their identification. CCS measurements of sodiated ions were carried out on a TW-IMMS instrument with nitrogen drift gas $\left({ }^{\mathrm{TW}} \mathrm{CCS}_{\mathrm{N} 2}\right)$ using a dextran homopolymer ladder as a calibrant. ${ }^{32,38}$ Le and BG epitopes were measured in triplicate and ${ }^{\mathrm{TW}} \mathrm{CCS}_{\mathrm{N} 2}$ values from all parent/fragment ions are presented in Table 1. The CCS deviation between individual replicates was below $1 \%$ and, therefore, well within the error of CCS estimation for oligosaccharides as previously described. ${ }^{38,39}$

In addition to neutral fucose loss fragments, the CID product ions Fuc-Gal ( $m / z$ 349, C-type), Gal-GlcNAc or GalNAc-Gal $(\mathrm{m} / \mathrm{z}, 406)$, and the loss of water from parent ions (-18 Da) were observed. Expectedly the $m / z 349$ ion was not detected in Le and Le $^{\mathrm{x}}$ samples, since they do not have Fuc-Gal linkages. The measured ${ }^{\mathrm{TW}} \mathrm{CCS}_{\mathrm{N} 2}$ values reflected the ATD data shown in Figure 3 and were consistent between experiments, demonstrating the robustness of the method. CCSs for $\mathrm{Le}^{\mathrm{b}}$ and $\mathrm{Le}^{\mathrm{y}}(\mathrm{m} / z, 698)$ were $252 \AA^{2}\left(252 \AA^{2}\right.$ for water loss) and $248 \AA^{2}\left(247 \AA^{2}\right.$ for water loss), respectively. As discussed above, $\mathrm{Le}^{\mathrm{y}}$ exhibits two drift peaks at $m / z 552$ with CCSs of $229 \AA^{2}$ and $216 \AA^{2}$. The Le $\mathrm{Le}^{\mathrm{y}}$ $\mathrm{m} / z, 552$ fragments would produce both $\mathrm{Le}^{\mathrm{x}}$ and $\mathrm{BG}-\mathrm{H}^{2}$ structures and correspondingly the CCSs were consistent with those measured for intact $\mathrm{Le}^{\mathrm{x}}\left(215 \AA^{2}\right)$ and BG-H ${ }^{2}\left(229 \AA^{2}\right)$. Similarly, the $\operatorname{Le}^{\mathrm{b}} \mathrm{m} / \mathrm{z}, 552$ fragment CCS $\left(224 \AA^{2}\right)$ was identical to the two possible $\mathrm{Le}^{\mathrm{a}}\left(223 \AA^{2}\right)$ and BG-H ${ }^{1}\left(224 \AA^{2}\right)$ precursor CCSs. The CCS values of the $\mathrm{m} / \mathrm{z}, 534$ ions (water loss from $\mathrm{m} / \mathrm{z}$ 552) were uniform for all structures $\left(\mathrm{Le}^{\mathrm{y}}: 218 \AA^{2}, \mathrm{Le}^{\mathrm{b}}: 219 \AA^{2}\right.$, $\mathrm{Le}^{\mathrm{a}}: 219 \AA^{2}, \mathrm{Le}^{\mathrm{x}}: 217 \AA^{2}, \mathrm{BG}-\mathrm{H}^{1}: 218 \AA^{2}, \mathrm{BG}-\mathrm{H}^{2}: 219 \AA^{2}$ ) except for BG-A, which with $222 \AA^{2}$ was considerably larger. Therefore, the $m / z, 534$ B-type fragments are only diagnostic for the BG-A epitope. The Gal-GlcNAc disaccharide $(\mathrm{m} / \mathrm{z}$ 406) CCSs on the other hand differed and were consistent between $\beta 1 \rightarrow 3$ $\left(189 \AA^{2}\right)$ or $\beta 1 \rightarrow 4$ linkages $\left(191 \AA^{2}\right)$, while the isomer GalNAc $\alpha 1 \rightarrow 3$ Gal $(m / z$ 406) from BG-A had an even larger CCS of $193 \AA^{2}$. Lastly, Fuc $\alpha 1 \rightarrow 2$ Gal fragment ions, which were present on all epitopes, except $\mathrm{Le}^{\mathrm{x}} / \mathrm{Le}^{\mathrm{a}}$, were constant with a CCS of $179 \AA^{2}$, but was unexpectedly dissimilar for BG-A $\left(177 \AA^{2}\right)$. It is unclear why the BG-A Fuc $\alpha 1 \rightarrow 2$ Gal CCS deviates, but it could result from the type of cleavage (i.e. Y-type opposed to C-type) or orientation of hydroxyl groups post fragmentation. However, these postulations are difficult to test experimentally. Together the combination of CCSs and MS/MS data are conclusively diagnostic of each epitope and should be considered benchmark values for the sequencing of larger glycan structures by IM-MS/MS.

Epitope Fragments from Milk Oligosaccharides. In order to test if the previously discussed epitope fragment ions are similarly diagnostic for larger structures, the fucosylated milk oligosaccharides FLNH (fucosyllacto-N-hexaose), DFLNH (difucosyllacto-N-hexaose) and TFLNH (trifucosyllacto-N-hexaose) were analysed. All oligosaccharides share the same lactoN-hexaose (LNH) backbone structure (Gal $1 \rightarrow 3 \mathrm{Glc}-$ $\mathrm{NAc} \beta 1 \rightarrow 3[\mathrm{Gal} \beta 1 \rightarrow 4 \mathrm{GlcNAc} \beta 1 \rightarrow 6] \mathrm{Gal} \beta 1 \rightarrow 4 \mathrm{Glc})$, which is fucosylated to give a $\mathrm{Le}^{\mathrm{x}}$ epitope on FLNH, $\mathrm{Le}^{\mathrm{x}}$ and $\mathrm{BG}-\mathrm{H}^{1}$ on DFLNH, and $\mathrm{Le}^{\mathrm{x}}$ and $\mathrm{Le}^{\mathrm{b}}$ on TFLNH.

Importantly, it is known for DFLNH that the primary CID product is the neutral loss of fucose $\mathrm{e}^{40}$ and we show here that this is also the case for CID of FLNH (Figure 4). However, some fragments of FLNH, DFLNH and TFLNH retain fucose and CCSs could be used to identify individual epitope structures. $\mathrm{Le}^{\mathrm{x}}$ is the only fucosylated structure on FLNH and CID produced fucosylated fragments $m / z \quad 876 \quad($ Gal $\beta 1 \rightarrow 4($ Fuc $\alpha 1 \rightarrow 3)$ Glc$\mathrm{NAc} \beta 1 \rightarrow 6 \mathrm{Gal} \beta 1 \rightarrow 4 \mathrm{Glc}) \quad$ and $\mathrm{m} / \mathrm{z} \quad 714$ $(\mathrm{Gal} \beta 1 \rightarrow 4$ (Fuc $\alpha 1 \rightarrow 3)$ GlcNAc $\beta 1 \rightarrow 6 \mathrm{Gal})$. The extracted ATDs of each ion gave single peaks (Figure 5). The CCSs of these ions were $279 \AA^{2}$ and $258 \AA^{2}$, respectively. Although the $m / z 534$ Btype $\mathrm{Le}^{\mathrm{x}}$ fragment is present in the MS/MS spectra (Figure 4A), the CCS of this fragment is not diagnostic as discussed above. The $m / z 876$ ion from DFLNH yielded two ATDs (Figure 5) with CCSs of $279 \AA^{2}$ and $290 \AA^{2}$ (Figure 4B) and can be assigned as $\mathrm{Gal} \beta 1 \rightarrow 4(\mathrm{Fuc} \alpha 1 \rightarrow 3) \mathrm{GlcNAc} \beta 1 \rightarrow 6 \mathrm{Gal} \beta 1 \rightarrow 4 \mathrm{Glc}$ (similar to FLNH) and Fuc $\alpha 1 \rightarrow 2 \mathrm{Gal} \beta 1 \rightarrow 3 \mathrm{Glc}-$ $\mathrm{NAc} \beta 1 \rightarrow 3 \mathrm{Gal} \beta 1 \rightarrow 4 \mathrm{Glc}$, which contains the $\mathrm{BG}-\mathrm{H}^{1}$ epitope. There was a single ATD peak for $m / z 714$ suggesting the presence of the Gal $\beta 1 \rightarrow 4$ (Fuc $\alpha 1 \rightarrow 3$ )GlcNAc $\beta 1 \rightarrow 6$ Gal fragment, similar

to 
A

章
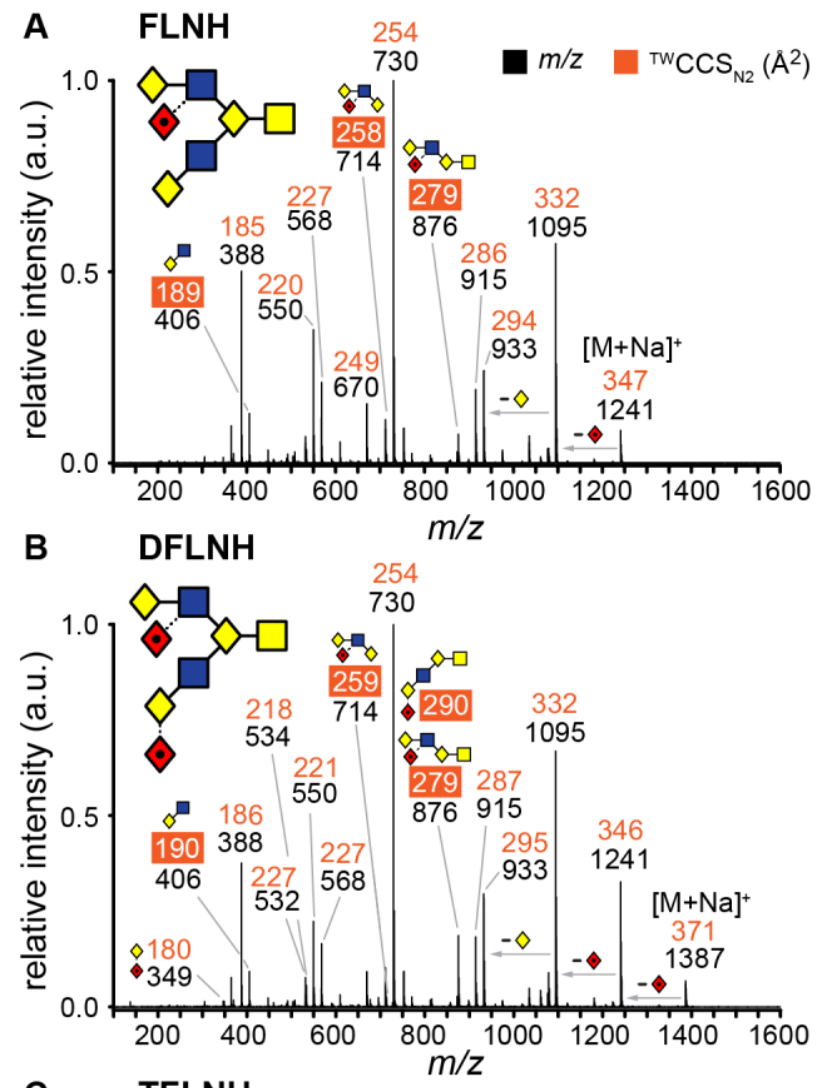

C TFLNH

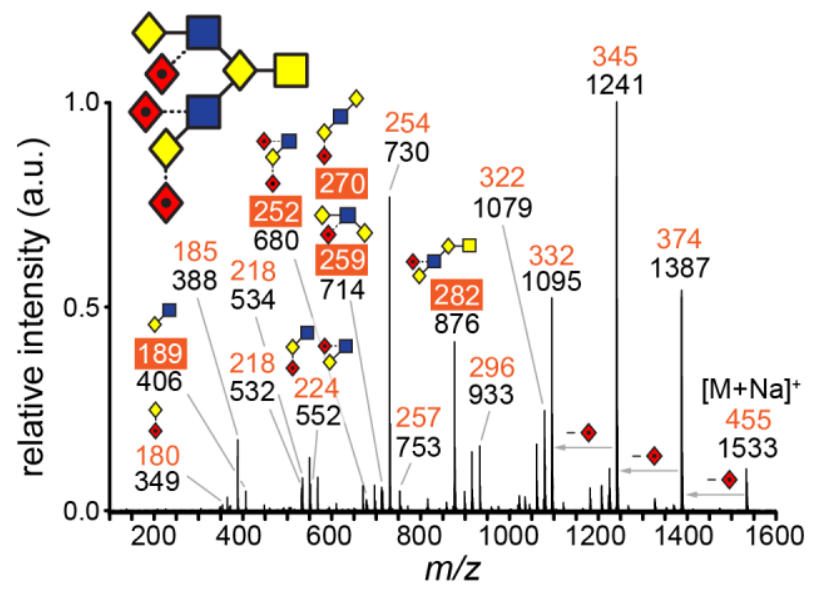

Figure 4. IM-MS/MS of FLNH (A), DFLNH (B) and TFLNH (C) milk oligosaccharides as $[\mathrm{M}+\mathrm{Na}]^{+}$ions. The $\mathrm{m} / \mathrm{z}$ values (black) with the corresponding ${ }^{\mathrm{TW}} \mathrm{CCS}_{\mathrm{N} 2}$ (orange) are shown. Glycan structures are represented using the Oxford system as defined in the legend to Figure 1. Diagnostic CCSs are highlighted by orange squares.

FLNH, but the presence of (Fuc $\alpha 1 \rightarrow 2 \mathrm{Gal} \beta 1 \rightarrow 3 \mathrm{Glc}-$ $\mathrm{NAc} \beta 1 \rightarrow 3 \mathrm{Gal})$ with the same CCS $\left(259 \AA^{2}\right)$ could not be excluded. However, based on the observation that $\mathrm{BG}-\mathrm{H}^{1}$ and $\mathrm{BG}-$ $\mathrm{H}^{1}$-containing fragments (such as $m / z 876$ from DFLNH) have greater CCSs than $\mathrm{Le}^{\mathrm{x}}$ equivalents, would suggest that the $\mathrm{m} / \mathrm{z}$ 714 from DFLNH is the Gal $\beta 1-4$ (Fuc $\alpha 1 \rightarrow 3$ )GlcNAc $\beta 1 \rightarrow 6 \mathrm{Gal}$ structure. Notable for both FLNH and DFLNH was the CCS of the $\mathrm{m} / \mathrm{z} 406$ fragment (Gal-GlcNAc, $190 \AA^{2}$ ), which indicates that this fragment primarily arises from cleavage at the lower antenna leading to a $\beta 1 \rightarrow 3$ linked structure.

IM-MS/MS of TFLNH (Figure 4C) supported this hypothesis

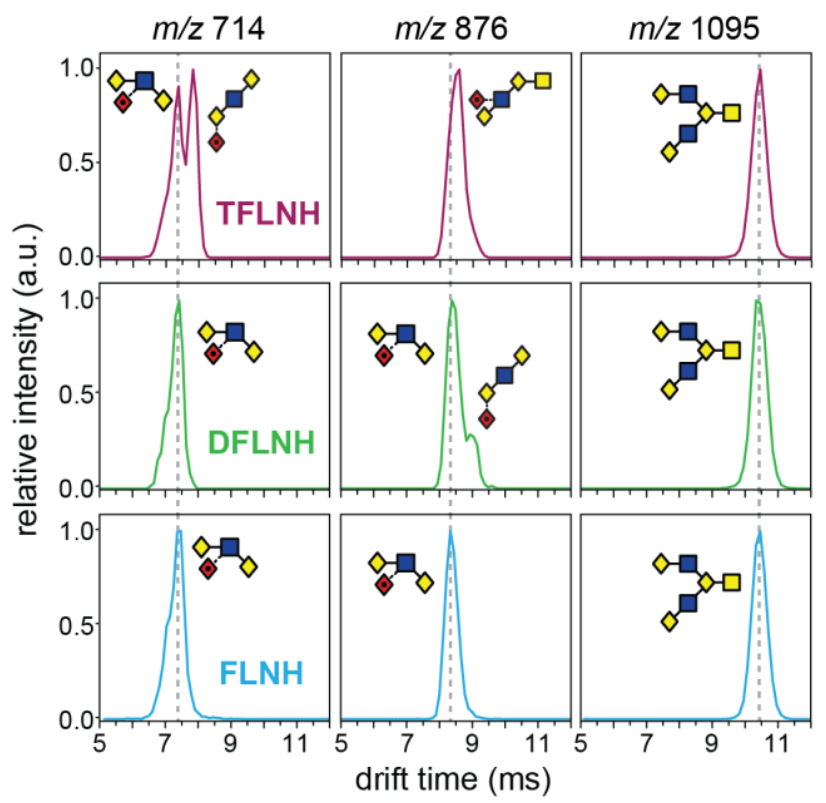

Figure 5. ATDs of diagnostic ions $m / z, 714,876$ and 1095 from FLNH (blue), DFLNH (green) and TFLNH (purple) milk oligosaccharides. Glycan structures are represented using the Oxford system as defined in the legend to Figure 1.

as demonstrated by the ATD and CCS $\left(282 \AA^{2}\right)$ of the $m / z 876$ ion which is smaller than the BG- $\mathrm{H}^{1}$ equivalent $\left(290 \AA^{2}\right)$ yet larger that the $\mathrm{Le}^{\mathrm{x}}$ containing ion $\left(279 \AA^{2}\right)$. The CCS of this structure $(\mathrm{Gal} \beta 1 \rightarrow 3$ (Fuc $\alpha 1 \rightarrow 4) \mathrm{GlcNAc} \beta 1 \rightarrow 3 \mathrm{Gal} \beta 1 \rightarrow 4 \mathrm{Glc})$ is diagnostic of the $\mathrm{Le}^{\mathrm{a}}$ epitope. There was no evidence of the $\mathrm{Le}^{\mathrm{x}}$ structure from the $\mathrm{m} / \mathrm{z} 552$ fragment, but is detected from the $m / z \quad 714$ fragment CCS $\left(259 \AA^{2}\right)$, which is similar to that obtained for FLNH. A second peak $\left(270 \AA^{2}\right)$ from $m / z, 714$ was identified (Figure 5) and is the (Fuc $\alpha 1 \rightarrow 2 \mathrm{Gal} \beta 1 \rightarrow 3 \mathrm{Glc}-$ $\mathrm{NAc} \beta 1 \rightarrow 3 \mathrm{Gal}$ ) fragment and again has a greater CCS owing to the presence of BG-H $\mathrm{H}^{1}$. Importantly the $m / z, 680$ ion $\left(252 \AA^{2}\right.$ ) accurately identifies the $\mathrm{Le}^{\mathrm{b}}$ epitope, matching the CCS fragment from the $\mathrm{Le}^{\mathrm{b}}$ standard in Table 1. Furthermore the absence of an $m / z 552$ doublet ATD refutes a Le ${ }^{y}$ epitope and the measured CCS of $224 \AA^{2}$ indicates the presence of a $\mathrm{BG}-\mathrm{H}^{1}$ or $\mathrm{Le}^{\mathrm{a}}$ epitope. Expectedly, the CCS of the Fuc $\alpha 1 \rightarrow 2 \mathrm{Gal} m / z, 349$ fragment from DFLNH and TFLNH was $180 \AA^{2}$ and, therefore, consistent with fragments generated from $\mathrm{BG}-\mathrm{H}^{1}$. Finally, the $m / z, 1095$ fragment ATDs from FLNH, DFLNH and TFLNH are equivalent as each oligosaccharide has the same LNH backbone structure. These data are to our knowledge the first example of CCS fragment assignments of milk oligosaccharides, which demonstrate that fucose linkages can be identified by characteristic CCS values of fragment ions.

Epitope Fragments from N-linked Glycans. Lastly, we investigated $\mathrm{N}$-glycans purified from human parotid gland, which are extensively fucosylated and differ among individuals depending on individual sector status. ${ }^{18,30,41}$. N-glycan samples used in this study have previously been characterized primarily as biand triantennary structures with up to five fucose residues on the core GlcNAc and the antennae. ${ }^{30}$ Salivary protein glycosylation is an important factor in pathogen interactions ${ }^{41}$, but direct links between glycan structure and susceptibility are debated. ${ }^{42,43}$ Mass spectrometry methods have failed to successfully discriminate $\mathrm{Le}^{\mathrm{a} / \mathrm{x}}$ or $\mathrm{Le}^{\mathrm{b} / \mathrm{y}}$ epitopes 


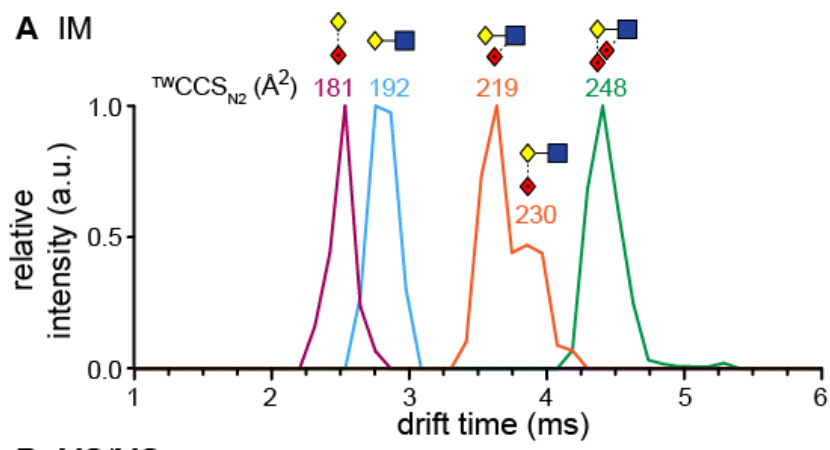

B MS/MS

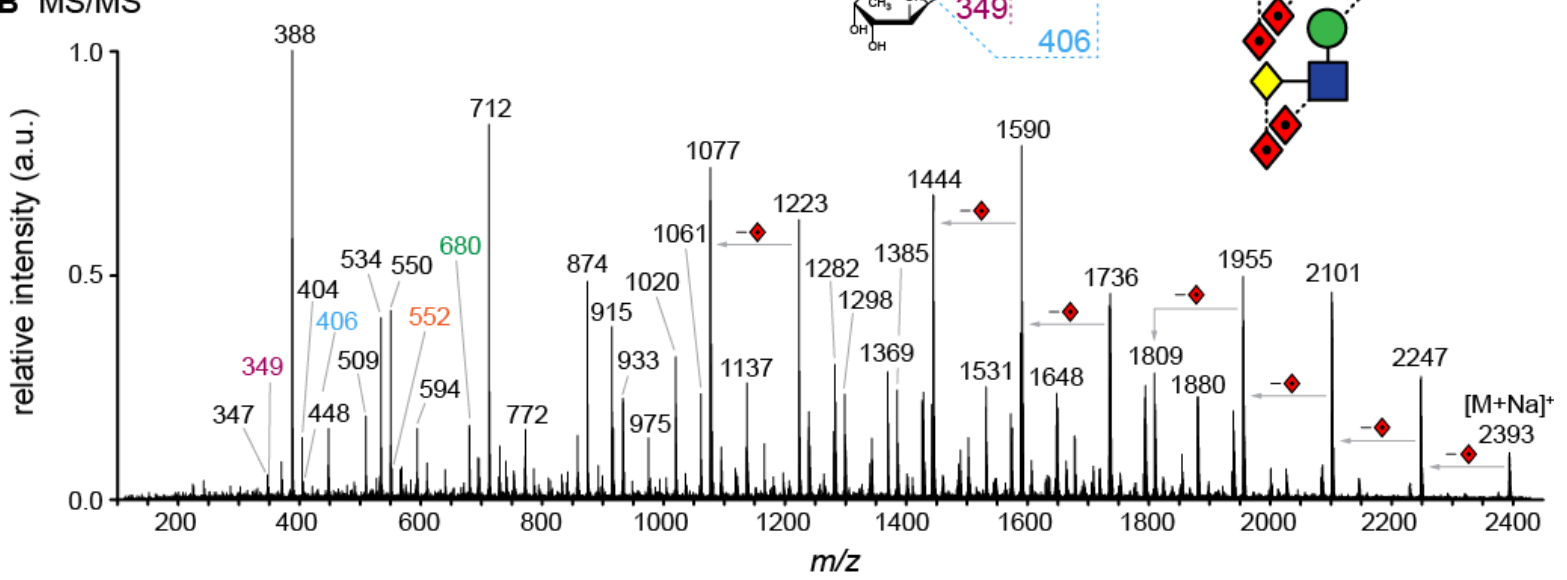

Figure 6. IM-MS/MS of the $\mathrm{m} / z 2394[\mathrm{M}+\mathrm{Na}]^{+} \mathrm{N}$-glycan from human parotid gland with A) ATDs and ${ }^{{ }^{T W}} \mathrm{CCSS}_{\mathrm{N} 2}$ of diagnostic fragments shown. B) MS/MS spectrum of $m / z, 2394$ with cartoon representation of the known precursor structure. Fragment assignments of the major ions are illustrated. Glycan structures are represented using the Oxford system ( $\square=$ GlcNAc, $\bigcirc=$ Man, $\diamond=\mathrm{Gal}, \diamond=\mathrm{Fuc})$.

on parotid $\mathrm{N}$-glycans ${ }^{18,41}$, which highlights the need for new approaches to characterize these terminal epitopes.

Tandem MS of the biantennary precursor $\mathrm{Fuc}_{5} \mathrm{Hex}_{5} \mathrm{HexNAc}_{4}$ at $\mathrm{m} / \mathrm{z}, 2394$ predominantly led to neutral loss fragments at $\mathrm{m} / \mathrm{z}$ 2248, 2012, 1956, and 1810 (Figure 6). However, also smaller fucosylated fragments were detected and their CCSs could be used to characterize the Le or BG epitope. These include the Ctype ions at $m / z 349$ (Fuc-Hex), 406 (Hex-HexNAc), 552 (FucHex-HexNAc), and 680 (2Fuc-Hex-HexNAc). The overall composition of the $\mathrm{N}$-glycan suggests four terminal fucose residues and one on the core GlcNAc. Therefore, the $m / z, 680$ fragment is either a $\mathrm{Le}^{\mathrm{b}}$ or $\mathrm{Le}^{\mathrm{y}}$ fragment, while the $m / z 552$ ion is a secondary fragment produced from $\mathrm{m} / z, 680$ (additional fucose loss), equivalent to those in Figure 3 and Table 1. An ATD with a single feature for $\mathrm{m} / \mathrm{z}, 680$ and the corresponding CCS (248 $\left.\AA^{2}\right)$ are consistent with a Le ${ }^{y}\left(247 \AA^{2}\right)$ but not a Le ${ }^{b}\left(252 \AA^{2}\right)$ epitope. More importantly an ATD exhibiting two features was observed for the $m / z, 552$ fragment, which is characteristic for the CID products of Le ${ }^{y}$ (Figure 3), with CCS values of $219 \AA^{2}$ and $230 \AA^{2}$, representing the $\mathrm{Le}^{\mathrm{x}}$ and $\mathrm{BG}-\mathrm{H}^{2}$ structures, respectively. The CCS of the $\mathrm{Le}^{\mathrm{x}}$ fragment from the parotid $\mathrm{N}$-glycan was slightly larger than that of the individual trisaccharide (215 $\AA^{2}$ ) shown above, which is likely a result of an overlap with a doubly charged species at $\mathrm{m} / z .550\left(\mathrm{Hex}_{2}\right.$-HexNAc fragment, $220 \AA^{2}$ ) in the extracted ATD of the $m / z 552$ fragment. Nonetheless, this observation does not impact the identification of the $\operatorname{Le}^{\mathrm{y}}$ structure due to the presence of multiple diagnostic ATD features. Overall, the CCS of $\mathrm{m} / z 349$ identifies Fuc $\alpha 1 \rightarrow 2$ Gal $\left(181 \AA^{2}\right)$, the $m / z 406$ fragment is a Gal $\alpha 1 \rightarrow 4$ GlcNAc species $\left(192 \AA^{2}\right.$ ), and taken together with the $m / z, 680$ fragment $\left(\mathrm{Le}^{\mathrm{y}}, 248 \AA^{2}\right)$ and the doublet ATD at $m / z, 552\left(\mathrm{Le}^{\mathrm{x}}, 219\right.$
$\AA^{2}$ and $\mathrm{BG}-\mathrm{H}^{2}, 230 \AA^{2}$ ), the presence of $\mathrm{Le}^{\mathrm{y}}$ epitopes on both antennae is demonstrated convincingly.

Tandem MS of the $\mathrm{Fuc}_{2} \mathrm{Hex}_{5} \mathrm{HexNAc}_{4}$ ion at $m / z 1956$ resulted in neutral loss of fucose residues from the parent ion and consequently the $m / z, 552$ C-type fragment was not abundant (Figure S-2). Although the $\mathrm{m} / z 534$ B-type fragment is present, again the CCS of this ion is not diagnostic. However, the absence of the $m / z, 349$ Fuc-Hex ion and the presence of an $m / z$ 406 CCS of $192 \AA^{2}$ suggests a Gal $\alpha 1 \rightarrow 4$ GlcNAc linkage and a Le $^{\mathrm{x}}$ structure. This result was expected as the Gal $\beta 1 \rightarrow 4$ (Fuc $\alpha 1 \rightarrow 3$ )GlcNAc structure $\left(\mathrm{Le}^{\mathrm{x}}\right)$ has been confirmed for this parotid biantennary $\mathrm{N}$-glycan. ${ }^{30}$ Accordingly, the CCS of the Gal $\beta 1 \rightarrow 4$ (Fuc $\alpha 1 \rightarrow 3$ )GlcNAc $\beta 1 \rightarrow 4$ Man fragment $\left(m / z 696,246 \AA^{2}\right)$ is potentially diagnostic for this epitope. As a final point, IM of complex N-glycans relies on generating ample diagnostic fucosylated CID products and owing to the propensity of fucose loss upon activation, the presence of these ions can be relatively low. Therefore monitoring CID activation energies is critically important for Le and BG identification by IM-MS/MS

\section{CONCLUSION}

Here we demonstrate that IM-MS/MS offers a new technique in glycan analysis by integrating gas-phase separation and CCS values with glycan CID fragmentation. We show that IM of individual Le and BG precursor and fragment ions are decidedly unique and systematically differentiate between isomers. Furthermore, we show that epitopes can be identified in multiply fucosylated parotid gland $\mathrm{N}$-glycans and milk oligosaccharides can be accurately sequenced. These data are significant and the 
incorporation of IM with current LC-MS/MS methods will undoubtedly improve glycomics analyses. For example, a similar approach revealed that $\alpha 2 \rightarrow 3$ and $\alpha 2 \rightarrow 6 N$-acetylneuraminic acid linkages can be differentiated by examining oxonium $[\mathrm{M}+\mathrm{H}]^{+}$fragments from glycopeptide precursor ions. ${ }^{23,44}$

There is sufficient and growing evidence that glycan isomers adopt distinct gas-phase structures allowing for separation and identification of previously indistinguishable structures ${ }^{22,28,45,46}$. To date the majority of IM studies for glycomics have focused on intact molecular ions, particularly for $\mathrm{N}$-glycans. Here we demonstrate that highly informative structural information lies beneath MS/MS fragmentation spectra when IM is explored. Together, these data can differentiate complex terminal fucose epitopes that have persistently challenged glycomics analyses. MS analysis of sodiated N-glycans is typically less popular owing to the scarcity of informative cross-ring fragments compared to negative ion analysis. On the other hand, analysis of negative ions for IM sequencing of glycoconjugates is less favourable compared to positive ions, because glycans ionize more efficiently as cation metal complexes ${ }^{47}$, readily form sodium adducts, and, most importantly, yield B- and C-type fucosylated fragments that can be compared to corresponding Le and BG ion CCS values.

Lastly, there are potential complications that would be resolved by incorporating LC prior to MS/MS and IM. Specifically, the presence of isomeric molecular ions would be difficult to resolve through a direct infusion ESI approach as the MS/MS spectrum would include data from multiple glycan structures. A 2-dimensional separation analysis by LC-IM-MS/MS has tremendous potential for glycomics and the data presented here establishes that IM information from fragment ions is exceedingly informative and provides a unique fingerprint that can assign unknown fucosylated epitopes from complex glycan mixtures. With the continued development of the method comes a tremendous need for software tools to calculate CCS values and since CCSs are absolute values, the sharing of datasets in the form of curated databases, such as GlycoMob ${ }^{34}$, is essential for continued success of ion mobility for glycomics.

\section{ASSOCIATED CONTENT}

\section{Supporting Information}

The Supporting Information Available: MS/MS spectra of synthetic epitopes (Figures S-1) and IM-MS data of the N-glycan from human parotid gland (Figure S-2). This material is available free of charge via the Internet at http://pubs. acs.org.

\section{AUTHOR INFORMATION}

\section{Corresponding Author}

*weston.struwe@bioch.ox.ac.uk (WBS) \& kevin.pagel@fu-berlin.de (KP) Fax: +44 (0)1865 285445 (WBS) \& +49 30 838472703 (KP)

\section{Author Contributions}

The manuscript was written through contributions of all authors. All authors have given approval to the final version of the manuscript.

\section{ACKNOWLEDGMENT}

W.S. and M.C. gratefully acknowledges a research grant from Against Breast Cancer (www.againstbreastcancer.org; UK Charity
1121258). M.C. is the Against Breast Cancer Fellow in Cancer Therapeutics at Oriel College, Oxford.

\section{REFERENCES}

(1) Takada, A.; Ohmori, K.; Yoneda, T.; Tsuyuoka, K.; Hasegawa, A.; Kiso, M.; Kannagi, R. Cancer Res. 1993, 53, 354-361.

(2) Sozzani, P.; Arisio, R.; Porpiglia, M.; Benedetto, C. Int. J. Surg. Pathol. 2008, 16, 365-374.

(3) Engel, P.; Dabelsteen, E.; Francis, D.; Graem, N. APMIS 1996, 104, 741-749.

(4) Itzkowitz, S. H.; Yuan, M.; Ferrell, L. D.; Ratcliffe, R. M.; Chung, Y. S.; Satake, K.; Umeyama, K.; Jones, R. T.; Kim, Y. S. J. Natl. Cancer Inst. 1987, 79, 425-434.

(5) Kim, Y. S.; Itzkowitz, S. H.; Yuan, M.; Chung, Y.; Satake, K.; Umeyama, K.; Hakomori, S. Cancer Res. 1988, 48, 475-482.

(6) Le Pendu, J.; Marionneau, S.; Cailleau-Thomas, A.; Rocher, J.; Le Moullac-Vaidye, B.; Clement, M. APMIS 2001, 109, 9-31.

(7) Myers, R. B.; Srivastava, S.; Grizzle, W. E. J. Urol. 1995, 153, 15721574.

(8) Ogawa, J.; Sano, A.; Inoue, H.; Koide, S. Ann. Thorac. Surg. 1995, 59, 412-415.

(9) Schuessler, M. H.; Pintado, S.; Welt, S.; Real, F. X.; Xu, M.; Melamed, M. R.; Lloyd, K. O.; Oettgen, H. F. Int. J. Cancer 1991, 47, 180-187.

(10) Xie, X.; Boysen, M.; Clausen, O. P.; Bryne, M. A. Laryngoscope 1999, 109, 1474-1480.

(11) Yin, B. W.; Finstad, C. L.; Kitamura, K.; Federici, M. G.;

Welshinger, M.; Kudryashov, V.; Hoskins, W. J.; Welt, S.; Lloyd, K. O. Int. J. Cancer 1996, 65, 406-412.

(12) Misek, D. E.; Patwa, T. H.; Lubman, D. M.; Simeone, D. M. J. Natl. Compr. Canc. Netw. 2007, 5, 1034-1041.

(13) Ashline, D. J.; Hanneman, A. J.; Zhang, H.; Reinhold, V. N. J. Am. Soc. Mass Spectrom. 2014, 25, 444-453.

(14) Reinhold, V.; Zhang, H.; Hanneman, A.; Ashline, D. Mol. Cell. Proteomics 2013, 12, 866-873.

(15) Jensen, P. H.; Karlsson, N. G.; Kolarich, D.; Packer, N. H. Nat. Protoc. 2012, 7, 1299-1310.

(16) Stockmann, H.; O'Flaherty, R.; Adamczyk, B.; Saldova, R.; Rudd, P. M. Integr. Biol. 2015, 7, 1026-1032.

(17) Karlsson, N. G.; Schulz, B. L.; Packer, N. H. J. Am. Soc. Mass Spectrom. 2004, 15, 659-672.

(18) Everest-Dass, A. V.; Jin, D.; Thaysen-Andersen, M.; Nevalainen, H.; Kolarich, D.; Packer, N. H. Glycobiology 2012, 22, 1465-1479.

(19) Wuhrer, M.; Koeleman, C. A.; Hokke, C. H.; Deelder, A. M. Rapid Commun. Mass Spectrom. 2006, 20, 1747-1754.

(20) Harvey, D. J.; Mattu, T. S.; Wormald, M. R.; Royle, L.; Dwek, R. A.; Rudd, P. M. Anal. Chem. 2002, 74, 734-740.

(21) Huang, Y.; Dodds, E. D. Anal. Chem. 2013, 85, 9728-9735.

(22) Hofmann, J.; Hahm, H. S.; Seeberger, P. H.; Pagel, K. Nature 2015, $526,241-244$.

(23) Hinneburg, H.; Hofmann, J.; Struwe, W. B.; Thader, A.; Altmann, F.; Varon Silva, D.; Seeberger, P. H.; Pagel, K.; Kolarich, D. Chem. Coтmun. 2016, 52, 4381-4384.

(24) Gray, C. J.; Thomas, B.; Upton, R.; Migas, L. G.; Eyers, C. E.; Barran, P. E.; Flitsch, S. L. Biochim. Biophys. Acta 2016, 1860, 16881709.

(25) Williams, J. P.; Grabenauer, M.; Holland, R. J.; Carpenter, C. J.; Wormald, M. R.; Giles, K.; Harvey, D. J.; Bateman, R. H.; Scrivens, J. H.; Bowers, M. T. Int. J. Mass Spectrom. 2010, 298, 119-127.

(26) Li, H.; Giles, K.; Bendiak, B.; Kaplan, K.; Siems, W. F.; Hill, H. H. Anal. Chem. 2012, 84, 3231-3239.

(27) Li, H. L.; Bendiak, B.; Siems, W. F.; Gang, D. R.; Hill, H. H. Rapid Commun. Mass Spectrom. 2013, 27, 2699-2709.

(28) Gaye, M. M.; Kurulugama, R.; Clemmer, D. E. Analyst 2015, 140, 6922-6932.

(29) Huang, Y.; Dodds, E. D. Anal. Chem. 2015, 87, 5664-5668.

(30) Guile, G. R.; Harvey, D. J.; O'Donnell, N.; Powell, A. K.; Hunter, A. P.; Zamze, S.; Fernandes, D. L.; Dwek, R. A.; Wing, D. R. Eur. J. Biochem. 1998, 258, 623-656.

(31) Hernandez, H.; Robinson, C. V. Nat. Protoc. 2007, 2, 715-726.

(32) Hofmann, J.; Struwe, W. B.; Scarff, C. A.; Scrivens, J. H.; Harvey, D. J.; Pagel, K. Anal. Chem. 2014, 86, 10789-10795.

(33) Thalassinos, K.; Grabenauer, M.; Slade, S. E.; Hilton, G. R.; Bowers, M. T.; Scrivens, J. H. Anal. Chem. 2009, 81, 248-254. 
(34) Struwe, W. B.; Pagel, K.; Benesch, J. L. P.; Harvey, D. J.; Campbell, M. P. Glycoconj. J. 2016, 33, 399-404.

(35) Struwe, W. B.; Agravat, S.; Aoki-Kinoshita, K. F.; Campbell, M. P. Costello, C. E.; Dell, A.; Ten, F.; Haslam, S. M.; Karlsson, N. G.; Khoo, K. H.; Kolarich, D.; Liu, Y.; McBride, R.; Novotny, M. V.; Packer, N. H.; Paulson, J. C.; Rapp, E.; Ranzinger, R.; Rudd, P. M.; Smith, D. F.;

Tiemeyer, M.; Wells, L.; York, W. S.; Zaia, J.; Kettner, C. Glycobiology 2016, 26, 907-910.

(36) Kolarich, D.; Rapp, E.; Struwe, W. B.; Haslam, S. M.; Zaia, J.;

McBride, R.; Agravat, S.; Campbell, M. P.; Kato, M.; Ranzinger, R.;

Kettner, C.; York, W. S. Molecular \& Cellular Proteomics 2013, 12, 991995.

(37) Harvey, D. J.; Merry, A. H.; Royle, L.; Campbell, M. P.; Dwek, R.

A.; Rudd, P. M. Proteomics 2009, 9, 3796-3801.

(38) Pagel, K.; Harvey, D. J. Anal. Chem. 2013, 85, 5138-5145.

(39) Gelb, A. S.; Jarratt, R. E.; Huang, Y.; Dodds, E. D. Anal. Chem.

2014, $86,11396-11402$
(40) Penn, S. G.; Cancilla, M. T.; Lebrilla, C. B. Anal. Chem. 1996, 68, 2331-2339.

(41) Albertolle, M. E.; Hassis, M. E.; Ng, C. J.; Cuison, S.; Williams, K. Prakobphol, A.; Dykstra, A. B.; Hall, S. C.; Niles, R. K.; Ewa Witkowska, H.; Fisher, S. J. Clin. Proteomics 2015, 12, 29.

(42) Burford-Mason, A. P.; Weber, J. C.; Willoughby, J. M. J. Med. Vet. Mycol. 1988, 26, 49-56.

(43) Shin, E. S.; Chung, S. C.; Kim, Y. K.; Lee, S. W.; Kho, H. S. Oral. Surg. Oral. Med. O. 2003, 96, 48-53.

(44) Guttman, M.; Lee, K. K. Anal. Chem. 2016, 88, 5212-5217.

(45) Struwe, W. B.; Benesch, J. L.; Harvey, D. J.; Pagel, K. Analyst 2015 , 140, 6799-6803.

(46) Plasencia, M. D.; Isailovic, D.; Merenbloom, S. I.; Mechref, Y.;

Novotny, M. V.; Clemmer, D. E. J. Am. Soc. Mass Spectrom. 2010, 21, 191-191.

(47) Harvey, D. J. J. Mass Spectrom. 2000, 35, 1178-1190.

\section{Abstract Graphic}

\section{IM-MS Fingerprinting}

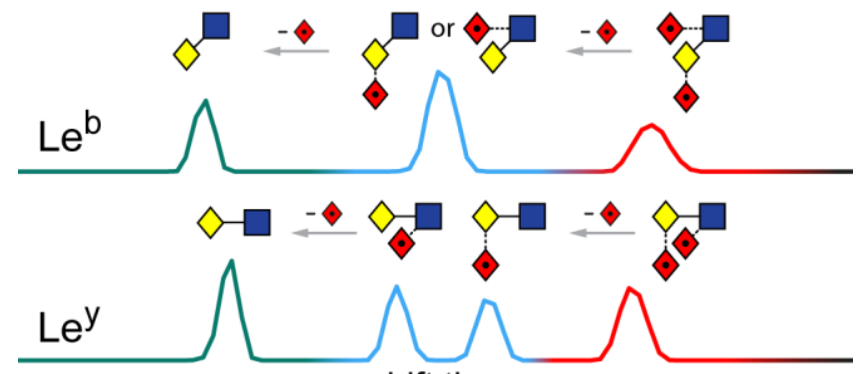

drift time 